\title{
Efisiensi Pemasaran Kopra Di Kecamatan Banggae Kabupaten Majene
}

\author{
Muhammad Fadhil Ramadhan', St Aisyah $\mathrm{R}^{2 *}$, Sahlan ${ }^{3}$, Sitti Arwati ${ }^{4}$ \\ 1,2,3,4 Prodi Agribisnis, Universitas Muhammadiyah Makassar \\ "Corresponding author: st.aisyah@unismuh.ac.id
}

\begin{abstract}
Abstrak: Penelitian ini bertujuan untuk menganalisis efisiensi pemasaran kopra di Kecamatan Banggae, Kabupaten Majene. Populasi penelitian ini adalah pengrajin kopra dimana pengambilan sampel dilakukan menggunakan snowball sampling. Data yang digunakan bersumber dari pelaku pemasaran kopra dan Badan Pusat Statistik baik data primer maupun data sekunder. Analisis deskriptif kuantitatif merupakan teknik analisis data yang digunakan untuk mengukur efisiensi pemasaran kopra di setiap saluran. Penelitian ini memberikan hasil bahwa saluran pemasaran pertama dan kedua memiliki kategori efisien dalam pemasaran kopra yang diukur melalui tingkat efisiensi sebesar 17,7\% saluran pemasaran pertama dan sebesar $21,1 \%$ saluran pemasaran kedua.
\end{abstract}

Kata Kunci: efisiensi, pemasaran, kopra

Abstract: This study aims to analyze the marketing efficiency of copra in Banggae District, Majene Regency. The population of this study were copra craftsmen where sampling was carried out using snowball sampling. The data used are sourced from copra marketing actors and the Central Statistics Agency, both primary data and secondary data. Quantitative descriptive analysis is a data analysis technique used to measure the efficiency of copra marketing in each channel. This study provides the results of the category that the first and second marketing have efficiency in copra marketing as measured by an efficiency level of $17.7 \%$ in the first marketing channel and $21.1 \%$ in the second marketing channel.

Keywords: efficiency, marketing, kopra

\section{PENDAHULUAN}

Subsektor perkebunan memiliki arti penting dalam pembangunan pertanian khususnya untuk peningkatan sumberdaya alam yang berkelanjutan dan lestari di negara berkembang. Dalam pembangunan nasional, suksektor perkebunan memiliki peranan lainnya terutama dalam penerimaan devisa negara, pemenuhan konsumsi dalam negeri, penyediaan lapangan kerja, kemakmuran dan kesejahteraan rakyat, pengoptimalan olahan sumberdaya alam berkelanjutan dan pencapaian nilai tambah yang berdaya saing (Widianti, dkk, 2008).

Kelapa merupakan komoditas perkebunan memiliki nilai ekonomi yang penting. Seluruh bagian tanaman kelapa termasuk daging buahnya bisa dimanfaatkan untuk pengolahan santan, kopra, dan minyak kelapa. Pada umumnya, kelapa yang telah dikeluarkan isinya dan dikeringkan digunakan sebagai bahan baku pembuatan minyak kelapa yang dinamakan kopra bagi masyarakat (Amin, 2009).

Pada umumnya, tahun 2019 tanaman perkebunan di Kecamatan Banggae, Kabupaten Majene didominasi oleh komoditas kelapa dan kakao. Kelapa dalam merupakan komoditas terbesar di Kecamatan Banggae dengan jumlah produksi sebesar 182 ton (Badan Pusat Statistik Kecamatan Banggae, 2020). Berdasarkan observasi di Kecamatan Bangge, Kabupaten Majene menunjukkan bahwa pada umumnya pengrajin kopra melakukan proses pemasaran melalui pedagang pengumpul, sementara pemasaran secara langsung ke pabrik minyak kelapa sangat 
minim. Beberapa penelitian terdahulu telah melakukan penelitian tentang pemasaran sektor pertanian maupun perkebunan baik nilai tambah, margin pemasaran, biaya pemasaran dan tataniaga kopra (Pohan, dkk, 2014; Sari, dkk, 2018; Arwati dan Syarif, 2016). Berkaitan dengan hal ini, Efisiensi pemasaran menjadi tolak ukur atas produktifitas proses pemasaran dengan membandingkan sumberdaya yang digunakan terhadap keluaran yang dihasilkan selama proses pemasaran (Silitonga dkk, 2020; Sangadji, 2016; Hastutik dkk, 2021; Sari dkk, 2021). Dengan demikian tujuan penelitian adalah untuk menganalisis efisiensi pemasaran kopra di Kecamatan Banggae, Kabupaten Majene.

\section{METODE PENELITIAN}

Penelitian dilakukan mulai bulan Juli sampai Oktober 2020 di Kecamatan Banggae, Kabupaten Majene dengan alasan sebagianmasyarakatdi wilayah tersebut berprofesi sebagai pengrajin kopra. Sampel dalam penelitian ini menggunakan metode sensus (sampel jenuh) berjumlah 11 orang pengrajin kopra. Sampel jenuh menurut sangadji (2018) adalah pengambilan sampel yang melibatkan seluruh anggota populasi menjadi sampel penelitian. Dengan demikian maka pengambilan sampel 10-15 atau 20-25 persen apabila subjek besar atau lebih dari 100 orang dan pengambilan sampel dibawah 100 orang sebaiknya diambil semuanya (Arikunto, 2006). Sementara sampel pedagang pengumpul dilakukan menggunakan snowball sampling dan ditemukan tiga orang pedagang pengumpul baik besar atau kecil masing-masing satu dan dua orang setelah penelusuran aliran barang. Dengan demikian, total sampel sebanyak 14 orang antara lain pedagang pengumpul dan pengrajin kopra.

Penelitian ini dianalisis menggunakan deskriptif kuantitatif yaitu untuk mengukur efisiensi pemasaran kopra di Kecamatan Banggae Kabupaten Majene. Kriteria efisiensi pemasaran dimana $<50 \%$ efisien dan $>50 \%$ tidak efisien. Perhitungan efisiensi pemasaran menggunakan rumus Roesmawaty (2011):

Efisiensi pemasaran $=\frac{\text { Biaya Total }}{\text { Nilai Produk Total }} \times 100 \%$

\section{HASIL DAN PEMBAHASAN}

Biaya Pemasaran

Adapun biaya pemasaran yaitu semua biaya yang dihitung dalam satuan rupiah per kilogram terdiri dari biaya kemasan, transportasi dan tenaga kerja. Biaya pemasaran kopra di Kecamatan Banggae Kabupaten Majene dapat dilihat pada Tabel 1.

Tabel 1. Biaya pemasaran kopra di Kecamatan Banggae Kabupaten Majene

\begin{tabular}{|c|c|c|c|c|c|c|}
\hline No & Uraian & Saluran & $\begin{array}{c}\text { Biaya rata-rata } \\
\text { tenaga kerja } \\
(\mathrm{Rp} / \mathrm{Kg})\end{array}$ & $\begin{array}{c}\text { Biaya rata-rata } \\
\text { kemasan } \\
(\mathrm{Rp} / \mathrm{Kg})\end{array}$ & $\begin{array}{c}\text { Biaya rata- } \\
\text { rata } \\
\text { transportasi } \\
(\mathrm{Rp} / \mathrm{Kg})\end{array}$ & $\begin{array}{c}\text { Total } \\
\text { biaya } \\
(\mathrm{Rp} / \mathrm{Kg})\end{array}$ \\
\hline & $\begin{array}{l}\text { Pedagang } \\
\text { Pengumpul }\end{array}$ & & & & & \\
\hline 1 & $\begin{array}{l}\text { Kecil } \\
\text { Pengrajin }\end{array}$ & 1 & 255 & 30 & 1.250 & 1.535 \\
\hline 2 & Kopra & 1 & 337 & 30 & 45 & 412 \\
\hline \multicolumn{6}{|c|}{ Total Biaya Pemasaran } & 1.947 \\
\hline 1 & $\begin{array}{l}\text { Pedagang } \\
\text { Pengumpul } \\
\text { Besar } \\
\text { Pedagang } \\
\text { Pengumpul }\end{array}$ & II & 312 & 30 & 833 & 1.175 \\
\hline 2 & Kecil & 11 & 225 & - & 600 & 825 \\
\hline 3 & Pengrajin & II & 255 & 30 & 42 & 327 \\
\hline
\end{tabular}




\begin{tabular}{cccccc}
\hline No Uraian & Saluran & $\begin{array}{c}\text { Biaya rata-rata } \\
\text { tenaga kerja } \\
(\mathrm{Rp} / \mathrm{Kg})\end{array}$ & $\begin{array}{c}\text { Biaya rata-rata } \\
\text { kemasan } \\
(\mathrm{Rp} / \mathrm{Kg})\end{array}$ & $\begin{array}{c}\text { Biaya rata- } \\
\text { rata } \\
\text { transportasi } \\
(\mathrm{Rp} / \mathrm{Kg})\end{array}$ & $\begin{array}{c}\text { Total } \\
\text { biaya } \\
(\mathrm{Rp} / \mathrm{Kg})\end{array}$ \\
\hline
\end{tabular}

Kopra

Total Biaya Pemasaran

2.327

Sumber : Data primer yang telah diolah, 2020

Tabel 1 menunjukkan bahwa biaya pemasaran terdiri dari dua saluran I dan II masingmasing sebesar Rp. $1.947 / \mathrm{Kg}$ dan Rp. $2.327 / \mathrm{Kg}$. Biaya tersebut terdiri dari biaya transportasi, kemasan, dan tenaga kerja. Pemasaran kopra mulai pengrajin kopra ke pedagang pengumpul merupakan saluran I. Hasil kopra diantarkan oleh pengrajin kopra menggunakan gerobak yang ditarik oleh motor ke pedagang pengumpul. Sementara pada saluran II, pedagang pengumpul mengeluarkan biaya transportasi yang paling banyak dikarenakan adanya biaya penyewaan truk yang membawa hasil kopra menuju ke Kota Makassar. Dengan demikian, saluran II memiliki saluran terpanjang hingga tiba ke konsumen yang berdampak pada tingginya biaya pemasaran. Hasil ini didukung oleh Dilon (2008), semakin tinggi biaya pemasaran komoditi akibat dari semakin panjang saluran tataniaga yang terlihat dari banyaknya kelembagaan yang terlibat dalam pemasaran komoditi. Hal ini akan berdampak pada keuntungan dari setiap kelembagaan tataniaga dan pada akhirnya konsumen akhir yang menanggung biaya pemasarannya. Pedagang pengumpul kecil pada saluran II mengeluarkan biaya tenaga kerja lebih kecil dibandingsaluran pemasaran I dikarenakan perbedaan upah harian yang diterima pedagang pengumpul kecil walau jam kerja dan hari kerjanya sama. Selain itu, pedagang pengumpul kecil mengeluarkan biaya transportasi dikarenakan adanya penyewaan mobil pickup dan pedagang pengumpul besar melakukan penyewaan mobil truk untuk membawa hasil kopra menuju Kota Makassar. Hal ini sesuai hasil penelitian Pohan, dkk (2014), biaya pemasaran saluran I mulai petani-pedagang pengumpul- pedagang lebih besar dibanding saluran II mulai petani-pedagang besarmasingmasing sebesar Rp. $2.172,24 / \mathrm{kg}$ dan Rp. 1.605,07/kg.

\section{Efisiensi Pemasaran}

Faktor kunci dalam mengukur efesiensi pemasaran adalah semua pelaku pemasaran memperoleh kesejahteraan. Pemasaran yang efisien apabila nilainya kurang dari $50 \%$ yang diperoleh dari pembagian total biaya dan nilai produk yang dipasarkan. Efisiensi pemasaran kopra di Kecamatan Banggae Kabupaten Majene dapat dilihat pada Tabel 2.

Tabel 2. Efisiensi pemasaran kopra di Kecamatan Banggae,Kabupaten Majene

\begin{tabular}{ccccc}
\hline No & Saluran Pemasaran & $\begin{array}{c}\text { Total Biaya } \\
(\mathrm{Rp} / \mathrm{Kg})\end{array}$ & $\begin{array}{c}\text { Total Nilai Jual } \\
(\mathrm{Rp} / \mathrm{Kg})\end{array}$ & Efisiensi (\%) \\
\hline 1 & 1 & 1.947 & 11.000 & 17,7 \\
2 & $1 \mathrm{l}$ & 2.327 & 11.000 & 21,1 \\
\hline
\end{tabular}

Sumber : Data primer yang telah diolah, 2020.

Tabel 2 menunjukkan bahwa nilai efisiensi pemasaran baik saluran I dan II memiliki nilai efisiensi kurang dari $50 \%$ masing-masing sebesar $17,7 \%$ dan $21,1 \%$. Hal ini sesuai dengan teori Roesmawaty (2011), pemasaran dikatakan masuk kategori efisien jika nilainya kurang dari 50\%. Saluran I lebih efisien dibandingkan saluran II dikarenakan biaya pemasaran yang lebih rendah masing-masing Rp. 1.947/kg dan Rp. 2.327/kg. Proses pemasaran kopra pada saluran I dimulai dari pengrajin kopra-pedagang pengumpul kecil-konsumen/industri di Kota Makassar berbeda pada saluran II dimulai dari pedagang pengumpul kecil-pedagang pengumpul besarkonsumen/industri. Dengan demikian, hal tersebut menyebabkan saluran pemasaran menjadi panjang akibat biaya pemasaran yang bertambah. Hal ini juga didukung oleh Prastio, dkk (2017) menyatakan bahwa keuntungan yang diterima saluran pemasaran I dan II masing-masing Rp.1.900/Kg dan Rp.1.200/Kg. Hal ini juga didukung hasil penelitian Pohan, dkk (2014) dan 
Chaerani (2016) menunjukkan bahwa pendeknya saluran pemasaran dan kecilnya biaya pemasaran yang dikelaurkan mengakibatkan saluran pemasaran menjadi efisien. Apabila nilai efisiensi pemasarankurang dari 50\% maka dikatakan pemasaran yang efisien.

\section{KESIMPULAN}

Nilai efisiensi pemasaran kurang $50 \%$ baik pada saluran pemasaran I dan II masing-masing sebesar $17,7 \%$ dan $21,1 \%$. Oleh karena itu, pemasaran kopra yang efisien dapat meningkatkan kesejahteraan pelaku mulai dari pengrajin kopra, pedagang pengumpul, dan konsumen.

\section{DAFTAR PUSTAKA}

Amin, Sarmidi. (2009). Cocopreneurship. Aneka Peluang Bisnis dari Kelapa. Lily Publisher. Yogyakarta.

Arikunto, S. (2006). Metode Penelitian Kualitatif. Bumi Aksara. Jakarta.

Arwati, S., \& Syarif, A. (2016). Sistem pemasaran dan nilai tambah produk olahan ubi jalar Kecamatan Polongbangkeng Utara Kabupaten Takalar. Jurnal Galung Tropika, 5(3), 178190.

Badan Pusat Statistik Kabupaten Banggae. 2020.

Chaerani, D. S. (2016). Marjin dan Efisiensi Pemasaran Kopra di Desa Simalegi Kecamatan Siberut Barat Kabupaten Kepulauan Mentawai. Jurnal Bibiet 1(2) Oktober 2016 (81-94).

Dilon.H.S., (2008). Manajemen Distribusi Produk Produk Agroindustri. Percetakan. TI-ITS Jakarta

Hastutik, S., Kusuma, G. P. E., Sudirman, A., Sangadji, S. S., Wardhana, A., Kartika, R. D., \& Hilal, N. Perilaku Konsumen (Tinjauan Konseptual \& Praktis).

Pohan, I. P., Sihombing, L., \& Sebayang, T. (2014). analisis nilai tambah dan pemasaran kopra (Kasus: Desa Silo baru, Kecamatan Silau Laut, Kabupaten Asahan). Journal of Agriculture and Agribusiness Socioeconomics, 2(9), 15123.

Prastio, H., Soetoro, S., \& Hardiyanto, T. (2017). Analisis Saluran Pemasaran Kopra(Studi Kasus di Desa Sindangsari Kecamatan Cimerak Kabupaten Pangandaran). Jurnal IImiah Mahasiswa Agroinfo Galuh, 3(1), 91-94.

Roesmawaty, H. (2011). Analisia efisiensi pemasaran pisang di Kecamatan Lengkiti Kabupaten Ogankomering Ulu. Jurnal Agrobisnis.3(5) : 1-9.

Sangadji, S. S. (2018). Profitability Analysis of Terubuk Farming (Saccharum Edule Hasskarl) in Subdistrict Tosa District of East Tidore of Tidore Island. Jurnal Akrab Juara, 3(2), 168-174.

Sangadji, S. S. (2016). Analisis Pengambilan Keputusan Konsumen terhadap Pembelian Jus Belimbing Winner Perkasa Indonesia Unggul Di Kota Depok (Doctoral dissertation, Universitas Mecu Buana Jakarta).

Sari, D. C., Wardhana, A., Darwin, M., Sulaiman, E., Rahmawan, G., Ridwan, M., ... \& Sangadji, S. S. (2021). Manajemen Pemasaran. Media Sains Indonesia.

Sari, N., Basri, M., Kambolong, M. (2018). Analisis Usaha Tataniaga Kopra Dalam Meningkatkan Pendapatan Keluarga Di Desa Oengkapala Kecamatan Wakorumba Utara Kabupaten Buton Utara. Jurnal BUSINESS UHO: Jurnal Administras Bisnis. Vol. 3 No. 2: 283-301.

Silitonga, H. P., Syamsuri, A. R., Halim, A., Haryani, D. S., Sangadji, S. S., \& Samad, A. (2020). PEMASARAN" Hasil pemikiran dari Para Dosen Berbagai Perguruan Tinggi di Indonesia (Book Chapter-)"(No. h7p6v). Center for Open Science.

Widianti, Noor dan Goni, (2008). Agribisnis Tanaman Perkebunan. Penebar Swadaya Jakarta 